Petja Maesch

\title{
Kodifikation und Anpassung des bulgarischen IPR an das Europäische Recht
}

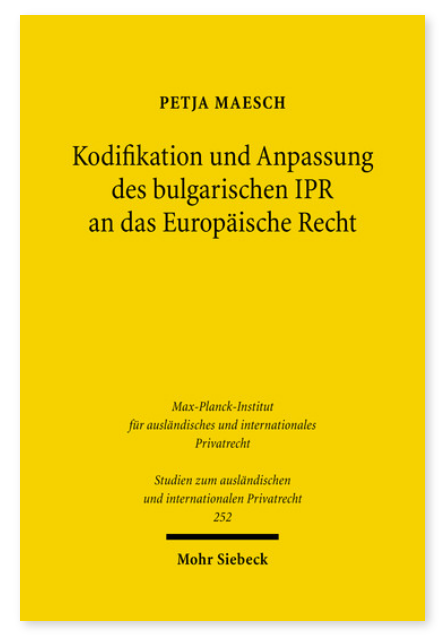

2010. XVIII, 366 Seiten. StudIPR 252

ISBN 978-3-16-151437-1

DOI 10.1628/978-3-16-151437-1

eBook PDF 89,00€

ISBN 978-3-16-150540-9

fadengeheftete Broschur $89,00 €$
Im Mai 2005 trat das bulgarische Gesetzbuch über das Internationale Privatrecht in Kraft, mit dem das bulgarische IPR erstmalig umfassend kodifiziert wurde. Die partiellen Modernisierungsversuche nach 1990 brachten keinen durchschlagenden Erfolg, weil dem bulgarischen IPR nach wie vor das Grundgerüst fehlte. Petja Maesch zeigt, dass das Gesetzbuch nun die Merkmale des bestehenden europäischen IPR/IZPR trägt: ipso iure -Anerkennung, Relativität des ordre public, Prinzip der engsten Verbindung, Verdrängung des Staatsangehörigkeitsprinzips etc. Solange das IPR in der Union noch nicht vollständig vereinheitlicht ist, bleibt zwar weiterhin Raum für das nationale Kollisionsrecht. Der Spielraum des nationalen Gesetzgebers wird jedoch immer enger, so dass die bulgarische IPR-Kodifikation nur im Gesamtkontext der europäischen Entwicklung beurteilt werden kann.

Petja Maesch Geboren 1976; Studium der Rechtswissenschaft an der Humboldt-Universität zu Berlin; 2009 Promotion; seit 2009 in der Rechtsabteilung der Stadt Mannheim tätig.
Jetzt bestellen:

https://mohrsiebeck.com/buch/kodifikation-und-anpassung-des-bulgarischen-ipr-an-das-europaeische-recht-

9783161514371?no_cache=1

order@mohrsiebeck.com

Telefon: $+49(0) 7071-923-17$

Telefax: $+49(0) 7071-51104$ 